\title{
A rare cause of neonatal cholestasis
}

\author{
R. Poppy Rejoice - S. Jeevan Kumar • R. Balamurali • \\ G. Ramkumar • K. Muthukumaran • P. Ganesh
}

Published online: 18 October 2013

(C) Indian Society of Gastroenterology 2013

Cholestasis associated with hyperpigmentation is an unusual combination, a 2-month-old female child born of nonconsanguineous marriage with no significant perinatal history presented with cholestasis and increased pigmentation all over the body since birth. On examination she was pale, icteric, and had generalized hyperpigmentation (Fig. 1) with normal external genitalia. She had elevated serum direct bilirubin and alkaline phosphatase with normal serum electrolytes. Biliary tract scanning, thyroid assay, and serum aldosterone were found to be normal. TORCH screening was negative. Serum cortisol ( 8 a.m.) was low at $<1 \mathrm{~g} / \mathrm{dL}$ while serum adrenocorticotropic hormone $(\mathrm{ACTH})$ was high at $>1,250 \mathrm{pg} / \mathrm{mL}$. Isolated cortisol deficiency (low cortisol, high $\mathrm{ACTH}$, normal aldosterone) can cause neonatal cholestasis [1,2]. The mechanism is not known; however, cortisol has been shown to influence bile formation and enhance bile flow in animal models. Delay in diagnosis leads to liver failure and death.

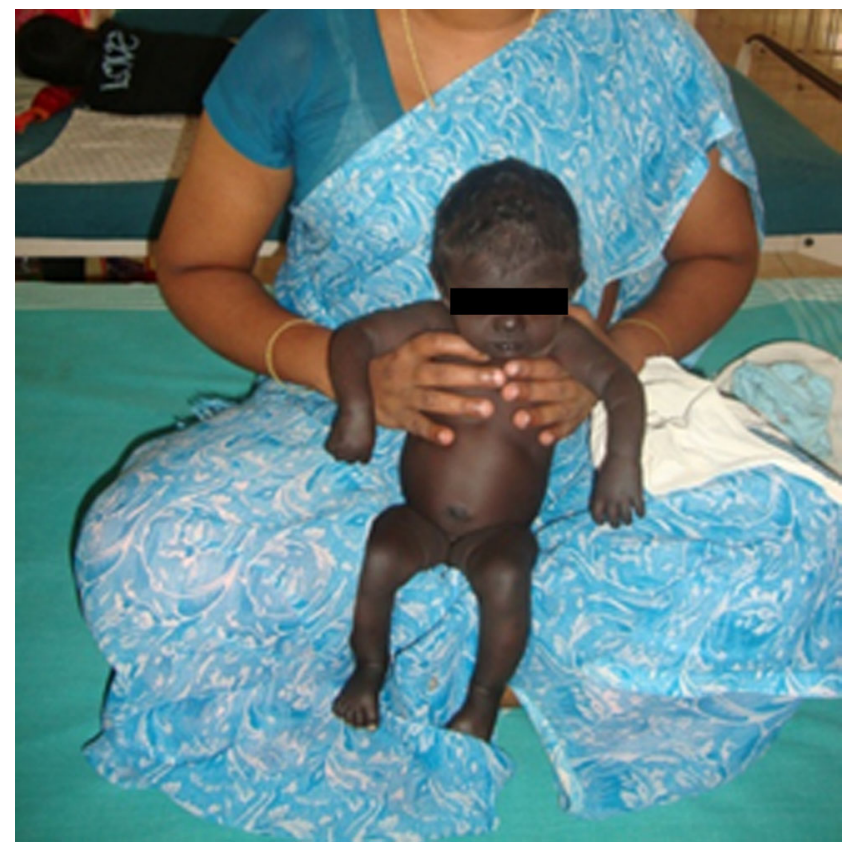

Fig. 1 Child with generalized hyperpigmentation

\section{References}

1. Berberoğlu M, Yiğit S, Ocal G, et al. Isolated deficiency of glucocorticoids presenting with cholestasis. Acta Paediatr Jpn. 1998;40:37880.

2. Al-Hussaini A, Almutairi A, Mursi A, Alghofely M, Asery A. Isolated cortisol deficiency: a rare cause of neonatal cholestasis. Saudi J Gastroenterol. 2012;18:339-41. 